\title{
Analisis Kinerja Lingkungan Dan Produktivitas Dengan Menggunakan Konsep Green And Lean Productivity
}

\author{
Muhammad Hanifuddin Hakim*, Ahmad Mubin \\ Jurusan Teknik Industri, Fakutas Teknik, Universitas Muhammadiyah Malang \\ Jl. Raya Tlogomas 246 Malang 65144 Jawa Timur \\ Surel: hanif_amik26@yahoo.com
}

\begin{abstract}
Regional Water Company (PDAM) Lamongan is a local company with main activity is to serve and provide clean water to communities through a system of pipes. Constraint occurs is in the process of drinking water treatment and wastewater sludge yield potential as a source of environmental pollution. Another problem is still limited because of PDAM services in 2013 is only capable of serving $4.7 \%$ of the total number of households (BPS population census of 2010). Taps need to increase the amount of water production in order to serve the wider community Lamongan. The concept of green productivity (GP) can be used in the search for solutions to increase productivity and protect the environment. The study begins by identifying the root cause of a lot of liquid waste and a low amount of water production, setting objectives and targets, choosing the resources and information available to arrange alternative green productivity. There are two alternatives, the selected alternative in this study are alternative 2 merge maximizing the raw water intake (pipe repair, purchase and installation of the intake screen 2 pump intake of government), Repair IPA II, and the use of wastewater that is the use of waste as material raw returned by first applying multilevel aeration technology to reduce levels of COD and BOD5 in wastewater. The productivity of the company in the first year after implementation of the selected alternative to $123 \%$, an increase of $14 \%$ compared to the year 2013 and the total value of the EPI index to 18.35 or increased 42.65, which means it meets effluent standards wastewater East Java Governor Regulation No. 72 of 2013. In addition the production of water PDAM also increased $69.8 \%$ over the previous year.
\end{abstract}

Keywords : Green Productivity, Liquid Waste, Story Aeration Technology, EPI, Productivity, PDAM

Abstrak
Perusahaan Daerah Air Minum (PDAM) Lamongan adalah perusahaan daerah
dengan aktivitas utama adalah melayani dan menyediakan air bersih kepada
masyarakat melalui sistem pipa. Permasalahn yang terjadi adalah pada proses
pengolahan air minum menghasilkan limbah cair maupun lumpur yang berpotensi
sebagai sumber pencemar lingkungan. Permasalahan lainnya adalah pelayanan
PDAM masih terbatas karena pada tahun 2013 hanya mampu melayani $4.7 \%$ dari
jumlah total rumah tangga (sensus penduduk BPS tahun 2010). PDAM perlu
meningkatkan jumlah air produksi agar bisa melayani masyarakat lamongan lebih
luas. Konsep green productivity (GP) dapat digunakan dalam mencari solusi untuk
meningkatkan produktivitas dan melindungi kelestarian lingkungan. Penelitian
diawali dengan mengidentifikasi sumber penyebab limbah cair banyak dan
rendahnya jumlah produksi air, menentukan tujuan dan target, memilih sumber
daya dan informasi yang tersedia untuk menyusun alternatif green productivity.
Terdapat 2 alternatif pilihan, alternatif terpilih dalam penelitian ini yaitualternatif
2 yakni melakukan penggabungan pemaksimalan intake air baku (perbaikan pipa,
pembelian screen intake dan pemasangan 2 pompa intake dari pemerintah),
Perbaikan IPA II, dan pemanfaatan limbah cair yaitu penggunaan limbah cair
sebagai bahan baku kembali dengan terlebih dahulu menerapkan teknologi aerasi
bertingkat untuk menurunkan kadar COD dan BOD5 pada limbah cair.


Produktivitas perusahaan pada tahun pertama setelah penerapan alternatif terpilih menjadi 123\% atau meningkat 14\% dibanding tahun 2013 dan total nilai indeks EPI menjadi 18.35 atau meningkat 42.65 yang berarti limbah cair sudah memenuhi standar baku air limbah Peraturan Gubernur Jawa Timur No 72 tahun 2013. Selain itu produksi air PDAM juga meningkat $69.8 \%$ dibanding tahun sebelumnya.

Kata Kunci : Green Productivity, Limbah Cair, Teknologi Aerasi Bertingkat, EPI, Produktivitas, PDAM

\section{Pendahuluan}

Setiap perusahaan tentunya harus dapat mengimplementasikan konsep efektivitas dan efisiensi dalam mencapai peningkatan produktivitas perusahaan karena hal ini sangat erat kaitannya dengan profit perusahaan. Seringkali keinginan ini menimbulkan gesekan pengaruh terhadap aspek lingkungan hidup. Asian Productivity Organization (APO) mengusung konsep green productivity dengan melakukan penghematan dan mencegah produk gagal beriringan dengan melestarikan lingkungan sehingga dapat meningkatkan produktivitas [1].

Perusahaan Daerah Air Minum (PDAM) Lamongan adalah perusahaan daerah dengan aktivitas utama adalah melayani dan menyediakan air bersih kepada masyarakat melalui sistem pipa. Wilayah Lamongan sendiri terdapat permasalahan sulitnya mencari air bersih dari sumber air tanah dikarenakan air tanah yang mayoritas payau atau berwarna karena mengandung unsur logam yang berbahaya. Sumber air baku PDAM yaitu Sungai Bengawan Solo yang menyumbang 100\% supply air sampai saat ini tidak pernah memenuhi syarat air minum (Permenkes nomor 492 tahun 2010) sehingga perlu proses pengolahan air. Proses pengolahan air minum tersebut menghasilkan limbah cair dan lumpur yang berpotensi sebagai pencemar lingkungan. Disisi lain, Berdasar data dari PDAM Lamongan, jumlah sambungan terpasang rumah tangga yaitu 14.351 sambungan. Data sensus penduduk BPS tahun 2010 menunjukkan jumlah rumah tangga yaitu 304.271. Jadi dapat diartikan bahwa sampai sejauh ini rumah tangga yang terlayani hanya $4.7 \%$ dari jumlah total rumah tangga. Sehingga PDAM perlu meningkatkan kuantitas produksi air minum agar dapat menjangkau dan melayani masyarakat yang lebih luas.

Peneliti bermaksud menggunakan konsep green productivity untuk peningkatan produktivitas sekaligus dalam upaya peningkatan kinerja lingkungan. Peningkatan produktivitas dilakukan untuk meningkatkan pemenuhan kebutuhan air PDAM yang semakin tinggi. Peningkatan kinerja lingkungan dilakukan untuk memastikan bahwa limbah yang dikeluarkan oleh PDAM dari proses pengolahan air tidak berpotensi mencemari lingkungan.

\section{Metode Penelitian}

Penelitian ini dilakukan melalui tujuh tahapan yaitu tahap pendahuluan, tahap pengumpulan data, tahap pengukuran produktivitas dan kinerja lingkungan, tahap identifikasi permasalahan, tahap penyusunan dan pemilihan alternatif, tahap analisis data, dan tahap penarikan kesimpulan. Pada tahap pendahuluan yang merupakan langkah awal dari penelitian dengan melakukan studi lapangan dan studi pustaka. Studi lapangan bertujuan mengetahui kondisi riil perusahaan khususnya proses yang banyak menghasilkan limbah. Setelah memperoleh gambaran dari survei awal dan mengetahui kendala-kendala yang dihadapi oleh perusahaan, maka dilakukan studi 
pustaka untuk mendukung penelitian yang akan dilakukan sehingga penelitian tersebut mempunyai dasar teori yang terarah dan memberikan hasil pemecahan yang optimal.

Tahap pengumpulan data yaitu melakukan pengambilan data dengan wawancara dan pengamatan langsung. Data tersebut meliputi gambaran umum perusahaan, proses produksi, input dan output hasil produksi, data hasil analisis kandungan zat kimia, dan penyebaran kuisioner. Kuisioner dimaksudkan untuk menentukan nilai bobot (weight) dari tingkat bahaya setiap zat kimia terhadap parameter keseimbangan lingkungan dan kesehatan manusia. Responden penelitian adalah ahli kimia lingkungan. Tahap pengukuran produktivitas dilakukan dengan membagi antara output total dengan input total yang meliputi penggunaan material, biaya tenaga kerja, dan penggunaan energy dan biaya lainnya. EPI merupakan tolak ukur kinerja dan performansi lingkungan suatu perusahaan. Indeks EPI dihitung melalui perkalian antara bobot (weight) tingkat bahaya suatu zat kimia dengan prosentase penyimpangan jumlah kandungan zat kimia dalam limbah.. Tahap identifikasi permasalahan yaitu mencari faktor-faktor apa saja yang mempengaruhi tingkat produktivitas dan kinerja lingkungan dengan menggunakan diagram sebab akibat. Setelah itu, tahap penyusunan alternatif-alternatif perbaikan yang disesuaikan dengan tujuan dan targetan yang telah ditetapkan. Pemilihan alternatif perbaikan menggunakan metode Benefit Cost Analysis (BCA). Dalam memilih alternatif solusi yang telah dimunculkan pada tahap sebelumnya dengan mempertimbangkan indeks Benefit Cost Rasio (BCR). Nilai perbandingan ini menunjukkan besarnya manfaat yang akan diperoleh perusahaan dibandingkan pengeluaran yang dibebankan. Pemilihan alternatif didasarkan atas nilai BCR yang paling tinggi. Estiminasi kontribusi alternatif terpilih terhadap produtivitas dan kinerja lingkungan. Setelah menemukan alternatif terbaik dan melakukan analisis teknisnya, selanjutnya dibuat estiminasi peningkatan terhadap angka produktivitas serta indeks EPI. Ini merupakan salah satu tujuan utama konsep Green Productivity, yaitu senantiasa meningkatkan produktivitas namun tetap memperhatikan kinerja lingkungan. Selanjutnya, penyusunan rencana implementasi yang merupakan kelanjutan dari analisis kelayakan teknis, dimana akan dibuat jadwal rencana implementasi. Pada tahap analisis dilakukan analisis dan pembahasan dari hasil pengolahan data. Sebagai tahap akhir, yaitu tahap penarikan kesimpulan hasil penelitian yang dilakukan.

\section{Hasil dan Pembahasan}

Perusahaan Daerah Air Minum Kabupaten (PDAM) Lamongan merupakan Badan Usaha Milik Pemerintahan Kabupaten Lamongan yang bergerak dibidang penyediaan air bersih. PDAM Lamongan dibentuk berdasarkan Peraturan Daerah Kabupaten Daerah Tingkat II Lamongan Nomor 5 tahun 1992 yang telah diperbarui dengan Peraturan Daerah Kabupaten Lamongan Nomor 5 tahun 2008. Instalasi Pengolahan Air Minum (IPAM) PDAM Kabupaten Lamongan terpusat di Kecamatan Lamongan Babat sekitar $29 \mathrm{~km}$ dari kota Lamongan. Lokasi tersebut terdapat 3 unit IPA yaitu IPA I kapasitas 90 l/dt dan IPA II kapasitas 120 l/dt yang keduanya terbuat dari beton bertulang serta IPA III kapasitas $110 \mathrm{l} / \mathrm{dt}$ yang terbuat dari baja. IPA II tidak bisa dioperasikan selama beberapa tahun terakhir dikarenakan mengalami kerusakan yang parah. IPA I mampu menyuplai air bersih 80 liter/detik sedangkan IPA III mampu menyuplai air bersih 100 liter/detik. Berikut ini jumlah produksi PDAM pada tahun 2013 : 
Tabel 1 Jumlah produksi air PDAM

\begin{tabular}{cc}
\hline Bulan & $\mathbf{m}^{\mathbf{3}}$ \\
\hline 1 & 428.985 \\
2 & 397.850 \\
3 & 390.478 \\
4 & 428.852 \\
5 & 480.069 \\
6 & 430.866 \\
7 & 417.067 \\
8 & 436.302 \\
9 & 450.576 \\
10 & 482.094 \\
11 & 482.094 \\
12 & 505.638 \\
Total & 5.330 .871 \\
Rata-rata & 444.239 \\
\hline
\end{tabular}

(Sumber PDAM)

\subsection{Process Flow Diagram (PFD)}

Process Flow Diagram (PFD) merupakan gambaran proses pengolahan air PDAM, dimulai dari penyedotan air baku Sungai Bengawan Solo menggunakan pompa sampai air siap untuk didistribusikan. Proses produksi pada IPAM ditunjukkan pada process flow diagram sebagai berikut:

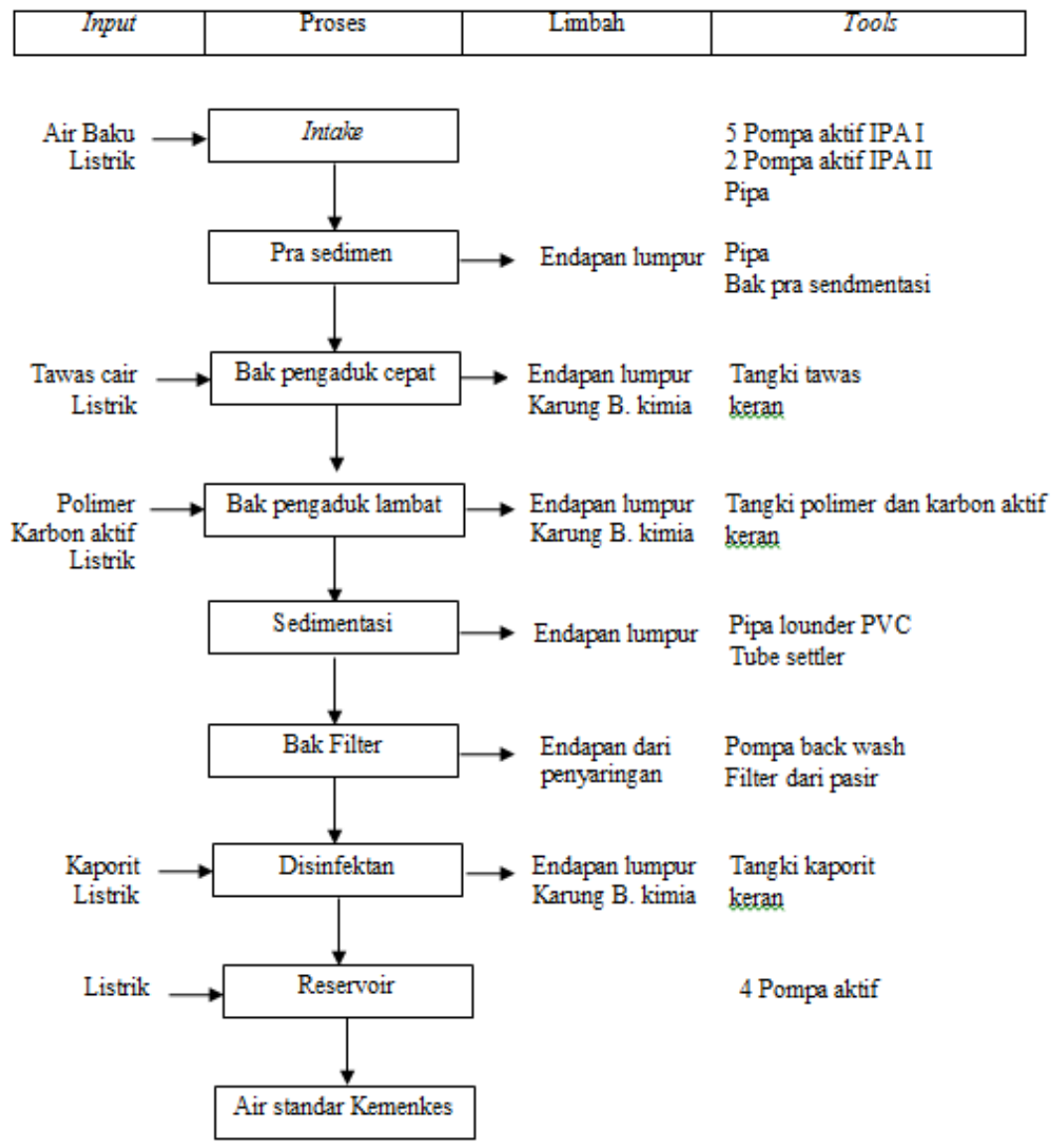

Gambar 1 Process flow diagram 


\subsection{Pengukuran Produktivitas Perusahaan}

Pengukuran produktivitas perusahaan diperoleh dari perhitungan rasio output perusahaan dibanding input perusahaan[2]. Perhitungan tingkat produktivitas perusahaan menggunakan rumus :

$$
\text { Produktivitas }=\frac{\text { output }}{\text { input }} \times 100 \%
$$

Hasil perhitungan pengukuran nilai produktivitas perusahaan pada tahun 2010-2013 dapat dilihat pada gambar 2 berikut:

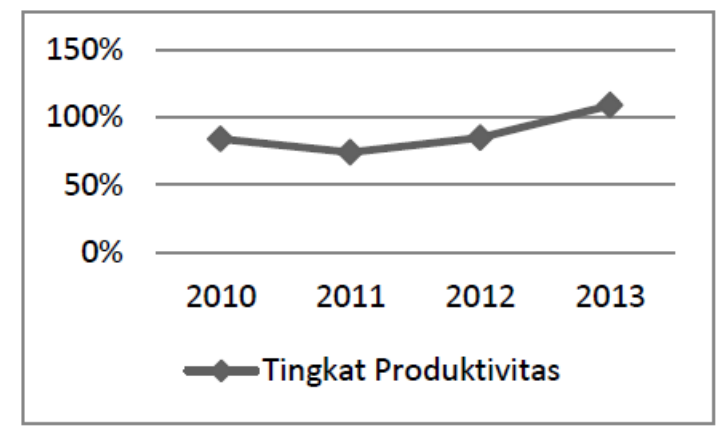

Gambar 2 Nilai produktivitas perusahaan

Berdasar gambar 2 dapat diketahui bahwa selama tahun 2010-2012 produktvitas perusahaan dibawah $100 \%$ yang artinya perusahaan mengalami kerugian dan pada tahun 2013 produktivitas perusahaan meningkat jauh dibandingkan tiga tahun sebelumnya yaitu 109\% yang artinya perusahaan mendapatkan keuntungan.

\subsection{Perhitungan Environmental Performance Indicator (EPI)}

Tidak ada dasar yang tetap (konsisten) dalam pemilihan indikator-indikator, jumlah indikator ataupun teknik-teknik pengukuran dan ketentuan standar[3]. EPI merefleksikan efisiensi lingkungan dari sebuah proses produksi yang melibatkan jumlah input dan output[4]. Karakter-karakter EPI yaitu (a) relevansi, (b) keakuratan analisis, (c) dapat diukur (measurebility), dan (d) dapat dibandingkan (comparability)[5]. Perhitungan indeks EPI dilakukan dengan mengalikan nilai penyimpangan antara standar BAPEDAL dengan hasil analisis perusahaan dengan bobot dari masing-masing kriteria limbah yang diperoleh melalui penyebaran kuisioner[6]. Indeks EPI dihitung dengan rumus:

$$
\text { Indeks EPI }=\sum_{i=1}^{k} W i p i
$$

Nilai $\mathrm{k}$ adalah jumlah kriteria limbah yang diajukan. Wi adalah bobot dari masing-masing kriteria. Bobot ini didapatkan melalui penyebaran kuesioner. Nilai Pi merupakan prosentase penyimpangan antara standar PERGUB JATIM No 72 tahun 2013 dengan hasil analisa.

$$
\mathrm{P} i=\frac{\text { Standar }- \text { Hasil Analisa }}{\text { Standar }} \times 100 \%
$$

Untuk mengetahui tingkat bahaya dari masing-masing parameter bagi manusia dan lingkungan diperlukan kuisioner guna pembobotan EPI Pembobotan EPI dilakukan melalui penyebaran kuisioner kepada 8 orang responden. Skala penilaiannya adalah 1- 
5, dimana semakin besar nilainya, maka semakin besar pula bahayanya bagi manusia dan lingkungan. Berdasarkan hasil uji validity dan reliability diketahui bahwa kuisioner yang dibuat valid dan reliable, yang berarti bahwa kuisioner yang sama dapat diberikan kepada responden yang lain tanpa memberikan tingkat penyimpangan yang signifikan. Hal ini ditunjukkan oleh nilai alpha yang lebih besar daripada nilai $\mathrm{r}$ tabel sebesar 0.707. Hasil perhitungan diperoleh nilai indeks EPI masing-masing kriteria sebagaimana pada Tabel 2 sebagai berikut:

Tabel 2 Perhitungan EPI Sebelum Perbaikan

\begin{tabular}{cccccc}
\hline Variable & Bobot & $\begin{array}{c}\text { Standar* } \\
\text { (mg/l) }\end{array}$ & $\begin{array}{c}\text { Hasil Analisa** } \\
\text { (mg/l) }\end{array}$ & $\begin{array}{c}\text { Penyimpangan } \\
\text { (Wi) }\end{array}$ & Indeks EPI \\
\hline Chlorine & 4.9 & 1 & 0.04 & $96 \%$ & 4.7 \\
Cupri & 4.8 & 2 & 0 & $100 \%$ & 4.8 \\
COD & 4.9 & 100 & 457.6 & $-358 \%$ & -17.5 \\
BOD5 & 4.8 & 50 & 258.7 & $-417 \%$ & -20 \\
PH & 3.7 & $6-9$ & 6 & $100 \%$ & 3.7 \\
Total Indeks & & & & & -24.3 \\
EPI & & & & & \\
\hline
\end{tabular}

* Standar Peraturan Gubernur Jatim No 72 Tahun 2013

** Lab. Jasa Tirta Malang dan Lab Kimia UMM

\subsection{Identifikasi Masalah dan Penyebab}

Untuk mengetahui permasalahan perusahaan baik pada peningkatan produktivitas maupun nilai indeks total EPI, maka dibutuhkan analisa untuk mengetahui penyebab dari dua permasalahan pokok tersebut. Tools yang digunakan untuk mengetahui penyebab permasalahan adalah diagram ishikawa[7].

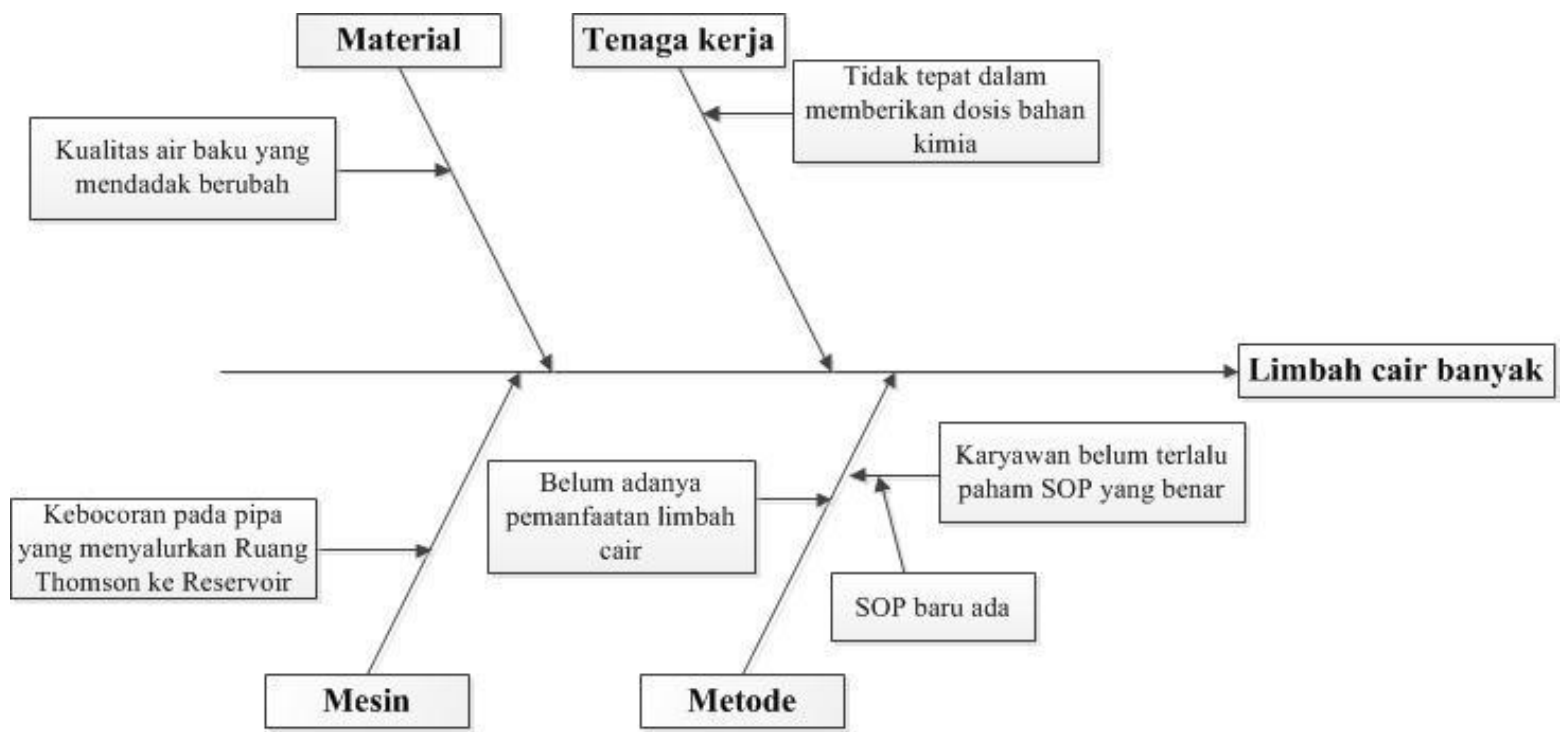

Gambar 3 Diagram Ishikawa limbah cair yang banyak 


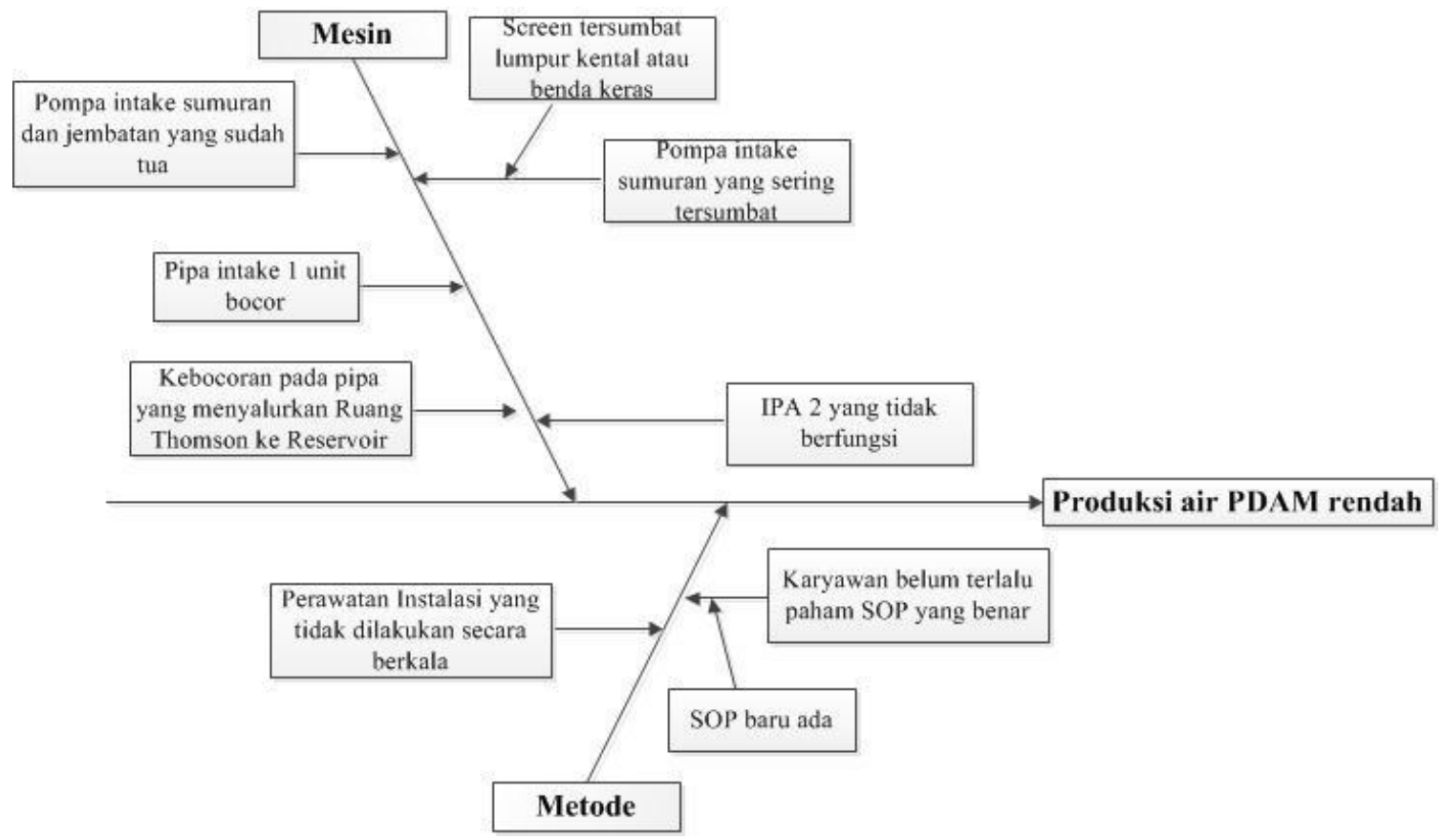

Gambar 4 Diagram Ishikawa jumlah produksi air yang rendah

Dari data PDAM diperoleh bahwa penyebab limbah cair banyak yaitu kualitas air baku yang mendadak berubah dan tidak tepat tenaga kerja memberikan dosis bahan kimia tidak menjadi penyebab signifikan limbah cair yang banyak. Setiap bulan dengan jumlah shift 90 kali hanya terjadi rata-rata satu shift atau tingkat probabilitasnya dalam satu bulan hanya 0.01 .

Faktor utama permasalahan produktivitas perusahaan sangat erat kaitannya dengan rendahnya kuantitas produksi air PDAM. Kuantitas produksi air PDAM yang rendah disebabkan karena tidak memadainya fasilitas yang ada dalam IPA Babat terutama Pompa intake ada yang sudah lebih dari 10 tahun, pipa yang bocor dan IPA 2 yang tidak bisa beroperasi lagi. Peningkatan produksi air menjadi keharusan karena memang hal tersebut menjadi tugas tersendiri bagi PDAM untuk terus meningkatkan kualitas pelayanan bagi pelanggan, apalagi sangat banyak warga Lamongan yang belum bisa menikmati air PDAM dikarenakan rendahnya kuantitas produksi air PDAM.

Perusahaan dapat dikatakan berada pada kondisi yang tidak baik, karena nilai produktivitas perusahaan masih rendah dan nilai indeks EPI bernilai negatif yaitu 24.3. Nilai indeks total EPI perusahaan yang negatif menunjukkan kinerja lingkungan perusahaan buruk karena tidak memenuhi standar Peraturan Gubernur JATIM No 72 2013 tentang limbah cair. Faktor utama nilai indeks EPI yang sangat rendah disebabkan kandungan COD dan BOD5 yang sangat tinggi pada limbah. Limbah cair mengandung COD dan BOD5 yang tinggi disebabkan karena memang air baku yang dipakai yaitu air Sungai Bengawan Solo mengandung COD dan BOD5 tinggi. Hal tersebut bukan disebabkan kesalahan pada proses produksinya tetapi disebabkan karena air baku yang sudah tercemar. jika dilihat dari jenis zat kimia yang tergandung dalam air limbah, terdapat zat chlorine yang semestinya tidak terkandung dalam limbah tersebut dikarenakan zat chlorine digunakan pada proses akhir yaitu tahap akhir sebelum masuk reservoir selain itu pada air baku juga tidak terdapat kandungan chlorine. Limbah yang dikeluarkan oleh pengolahan air PDAM adalah limbah cair dan lumpur. Prosentase volume limbah tersebut 90\% limbah cair, 10\% limbah lumpur dengan jumlah limbah cair \pm 7 liter/detik. 
Berdasarkan permasalahan pokok perusahaan terkait peningkatan produktivitas dan kinerja lingkungan serta penyebab yang sudah terjawab dalam diagram ishikawa maka ditentukan tujuan serta target yang ingin dicapai. Berikut tujuan dan target tersebut:

Tabel 3 Tujuan dan Target

\begin{tabular}{ccc}
\hline No & Tujuan & Target \\
\hline 1 & Meningkatkan produksi kuantitas air & Kuantitas air meningkat 3\% \\
2 & Pemanfaatan limbah PDAM & Mampu menurunkan jumlah limbah \\
& minimal 50\% \\
\hline
\end{tabular}

Penyusunan alternatif solusi

1. Pemaksimalan intake air baku (perbaikan pipa, pembelian screen intake dan penggantian 2 pompa intake)

Kondisi pipa intake jembatan yang bocor memiliki dampak yang lumayan pada kelancaran proses pendistribusian air baku ke pra sedimen. Kebocoran pipa tersebut berdampak pada air yang terbuang percuma \pm 2 liter/detik. Hal tersebut harus segera diatasi untuk mengatasi pemborosan pada salah satu proses produksi.

Kondisi pipa yang menyalurkan air setelah proses pemberian zat chlorine pada ruang Thomson ke Reservoir juga mengalami kebocoran yang lebih parah dibanding pada pipa intake. Kebocoran pipa tersebut menyebabkan air yang telah melewati proses koagulasi-flokulasi terbuang percuma ke penambungan limbah.Hal tersebut juga tentunya merupakan pemborosan yang harus segera diatasi untuk mengefisiensi proses produksi karena kebocoran yang terjadi mencapai 3 liter/detik. Kebocoran pada pipa ini juga menjadi penyebab kenapa air limbah cair yang besar dan zat chlorine dan kalsium yang terkandung pada limbah cair. Apabila kedua pipa tersebut diperbaiki agar tidak bocor kembali maka penambahan kuantitas air produksi mencapai 5 liter/detik atau 157.680.000 liter/tahun atau $157.680 \mathrm{~m} 3$ sehingga produksi air meningkat $3 \%$ dari total produksi air tahun 2013. Apabila hal ini diterapkan maka kuantitas limbah cair turun sebesar $43 \%$.

Pompa intake yang sudah lebih dari 10 tahun juga perlu diganti agar daya pompa menarik air baku jauh meningkat. Pompa tersebut juga sering mengalami kendala dalam menyedot air baku yang bercampur dengan kotoran-kotoran yang lumayan besar sehingga menyebabkan waktu yang terbuang untuk membersihkan sumbatan tersebut. Untuk mencegah banyaknya kotoran yang masuk ke pompa sehingga menyumbat pompa intake maka perlu pembelian screen intake.

\section{Perbaikan IPA 2}

IPA 2 yang sudah terbengkalai lebih dari 5 tahun perlu segera diperbaiki agar kuantitas air PDAM meningkat dan mampu melayani masyarakat lebih banyak lagi. IPA 2 memiliki kapasitas produksi air 120 l/dtk dan air produksi air minum $110 \mathrm{l} / \mathrm{dtk}$. Apabila IPA 2 ini dapat berfungsi kembali maka kuantitas air PDAM akan bertambah 3.468.960 m3 tiap tahun atau dapat meningkatkan kuantitas produksi air PDAM 65\% dari tahun 2013.

\section{Pemanfaatan limbah cair}

Limbah cair secara kuantitas lumayan besar, rata-rata bisa mencapai 7 liter/detik. Jika kebocoran pada pipa yang menghubungkan ke Reservoir diperbaiki maka limbah cair dapat turun menjadi 4 liter/detik. Kandungan limbah bisa dikatakan buruk karena nilai total indeks EPI mencapai -24.3. Apabila kandungan COD dan BOD5 pada limbah bisa dikurangi sampai batas standar PERGUB JATIM dan zat chlorine 
bisa diminimalisir maka limbah cair tersebut bisa dimanfaatkan kembali menjadi air baku sehingga bisa dialirkan ke bak prasedimen. Kandungan COD dan BOD5 yang tinggi bisa dikurangi dengan menerapkan teknologi Aerasi bertingkat. Jika teknologi tersebut diterapkan pada limbah cair maka kandungan COD dan BOD5 bisa turun hingga 90\% [8]. Penggunaan zat chlorine pada proses koagulasi-flokuasi sangat tidak disarankan karena dapat menimbulkan munculnya zat yang berbahaya pada air hasil olahan. Maka dari itu sebelum pemanfaatan limbah cair tersebut maka kandungan zat chlorine harus diminimalisir. Setelah ditelusuri penyebab zat chlorine yang terdapat pada limbah cair bukan disebabkan kandungan pada air baku sungai bengawan solo tetapi hal tersebut disebabkan bocornya pipa pada ruang Thomson. Maka agar limbah cair bisa dimanfaatkan, dibutuhkan peralatan berupa pipa dan mesin diesel untuk mengalirkan limbah cair pada bak aerasi bertingkat.

\subsection{Penyusunan dan Estimasi Kontribusi Alternatif Alternatif 1}

Alternatif 1 adalah alternatif yang menggabungkan pemaksimalan intake air baku (perbaikan pipa, pembelian screen intake dan pemasangan 2 pompa intake dari pemerintah), pemanfaatan limbah cair. Alternatif 1 memiliki umur ekonomis 10 tahun. Total penambahan jumlah produksi air $252.288 \mathrm{~m} 3$ atau meningkat $4.7 \%$ dibanding tahun 2013. Apabila alternatif 1 diterapkan maka EPI akan meningkat dari total indeks EPI -24.3 menjadi 18.35, atau meningkat 42.65 dibanding indeks EPI awal. Sedangkan dalam ukuran produktivitas, meskipun biaya pegoperasian cukup mahal akan tetapi nilai produktiktivitas pada tahun pertama meningkat sebesar $3 \%$ dari nilai produktivitas awal 109\% menjadi $112 \%$.

\section{Alternatif 2}

Alternatif 2 adalah alternatif yang menggabungkan pemaksimalan intake air baku (perbaikan pipa, pembelian screen intake dan pemasangan 2 pompa intake dari pemerintah), Perbaikan IPA 2, dan pemanfaatan limbah cair. Alternatif 2 memiliki umur ekonomis 10 tahun. Total penambahan jumlah produksi air $3.468 .960 \mathrm{~m} 3=$ $3.721 .248 \mathrm{~m} 3$ atau meningkat $69.8 \%$ dibanding tahun 2013. Apabila alternatif 1 diterapkan maka EPI akan meningkat dari total indeks EPI -24.3 menjadi 18.35, atau meningkat 42.65 dibanding indeks EPI awal. Sedangkan dalam ukuran produktivitas, meskipun biaya pegoperasian cukup mahal akan tetapi nilai produktiktivitas pada tahun pertama meningkat sebesar $14 \%$ dari nilai produktivitas awal 109\% menjadi $123 \%$.

Tabel 4 Perhitungan EPI Setelah Penerapan Alternatif 1 dan 2

\begin{tabular}{cccccc}
\hline Variable & Bobot & $\begin{array}{c}\text { Standar* } \\
\text { (mg/l) }\end{array}$ & $\begin{array}{c}\text { Hasil Analisa** } \\
\text { (mg/l) }\end{array}$ & $\begin{array}{c}\text { Penyimpangan } \\
\text { (Wi) }\end{array}$ & Indeks EPI \\
\hline Chlorine & 4.9 & 1 & 0 & $100 \%$ & 4.9 \\
Cupri & 4.8 & 2 & 0 & $100 \%$ & 4.8 \\
COD & 4.9 & 100 & 45.8 & $54 \%$ & 2.65 \\
BOD5 & 4.8 & 50 & 25.9 & $48 \%$ & 2.3 \\
PH & 3.7 & $6-9$ & 6 & $100 \%$ & 3.7 \\
Total Indeks & & & & & 18.5 \\
EPI & & & & & \\
\hline
\end{tabular}

\footnotetext{
* Standar Peraturan Gubernur Jatim No 72 Tahun 2013
}

** Lab. Jasa Tirta Malang dan Lab Kimia UMM

EPI sebelum $=-24.3$, EPI sesudah $=18.35$ peningkatan EPI 42.65 dibanding EPI sebelumnya. 


\subsection{Pemilihan Alternatif}

Dua alternatif yang sudah dibahas sebelumnya harus dipilih salah satu yang terbaik menggunakan benefit cost rasio (BCR)[9]. Alternatif-alternatif dinilai layak apabila rasio antara manfaat terhadap biaya yang dibutuhkan lebih besar dari satu[10]. Kedua alternatif dianggap layak karena nilai BCR alternatif satu sebesar 2.85 sedangkan untuk alternatif dua sebesar 1.51. Dua alternatif tersebut harus dipilih mana yang terbaik dengan cara membandingkan kedua alternatif tersebut. Berikut manfaat dan biaya kedua alternatif :

Tabel 5 Data manfaat dan biaya alternatif pilihan

\begin{tabular}{cccc}
\hline Alternatif & Manfaatt & Biaya & BCR \\
\hline 1 & Rp. 5.245.698.240 & Rp. 1.950.824.512 & 2.7 \\
2 & Rp. 66.908 .039 .040 & Rp. 44.349.928.839 & 1.51 \\
\hline
\end{tabular}

Langkah pertama, membandingkan alternatif 1 dengan alternatif 0 atau do nothing. Peningkatan manfaat dari alternatif 0 ke alternatif 1 adalah Rp. Rp. 5.245.698.240 dan peningkatan ongkosnya adalah Rp. 1.950.824.512 dengan demikian maka BCR peningkatan tersebut adalah:

$$
\mathrm{B} / \mathrm{C}_{1-0}=\frac{R p \cdot 5 \cdot 245 \cdot 698.240}{R p \cdot 1.950 .824 .512}=2.7
$$

karena $\mathrm{B} / \mathrm{C} \quad$ 1-0 $\geq 1$ maka alternatif 1 dipilih. Selanjutnya alternatif 1 dibandingkan dengan alternatif 2 sehingga diperoleh BCR meningkat sebagai berikut:

$$
\begin{aligned}
\mathrm{B} / \mathrm{C}_{2-1} & =\frac{R p \cdot 66.908 .039 .040-R p \cdot 5 \cdot 245.698 .240}{R p .44 .349 .928 .839-R p \cdot 1.950 .824 .512} \\
& =\frac{R p .61 .662 .340 .800}{R p .42 .339 .104 .327}=1.45
\end{aligned}
$$

Nilai B/C 2-1 lebih besar dari satu sehingga alternatif 2 lebih baik dari alternatif 1 , dengan demikian maka alternatif 2 dipilih.

\section{Simpulan}

Berdasarkan hasil analisis dapat disimpulkan bahwa faktor yang berpengaruh terhadap produktivitas dan kinerja lingkungan perusahaan adalah kinerja ketel uap (boiler), dan pengolahan limbah cair. Berdasarkan metode Benefit Cost Analysis maka alternatif 2 yang terpilih yaitu penggabungan pemaksimalan intake air baku (perbaikan pipa, pembelian screen intake dan pemasangan 2 pompa intake dari pemerintah), Perbaikan IPA 2, dan pemanfaatan limbah cair

\section{Referensi}

[1] A. P. Organization, Green Productivity Training Manual: Tokyo:APO 2001.

[2] M. Rüßmann, M. Lorenz, P. Gerbert, M. Waldner, J. Justus, P. Engel, et al., "Industry 4.0: The future of productivity and growth in manufacturing industries," Boston Consulting Group, vol. 9, 2015. 
[3] N. Semenova and L. G. Hassel, "On the validity of environmental performance metrics," Journal of Business Ethics, vol. 132, pp. 249-258, 2015.

[4] M. Puig, C. Wooldridge, and R. M. Darbra, "Identification and selection of environmental performance indicators for sustainable port development," Marine pollution bulletin, vol. 81, pp. 124-130, 2014.

[5] S. Bracco, F. Delfino, F. Pampararo, M. Robba, and M. Rossi, "A mathematical model for the optimal operation of the University of Genoa Smart Polygeneration Microgrid: Evaluation of technical, economic and environmental performance indicators," Energy, vol. 64, pp. 912-922, 2014.

[6] J. Hřebíček, J. Soukopová, M. Štencl, and O. Trenz, "Corporate key performance indicators for environmental management and reporting," Acta Universitatis Agriculturae et Silviculturae Mendelianae Brunensis, vol. 59, pp. 99-108, 2014.

[7] D. N. Tran and L. A. Bero, "Barriers and facilitators to the quality use of essential medicines for maternal health in low-resource countries: An Ishikawa framework," Journal of global health, vol. 5, 2015.

[8] A. Ismail, "Pengolahan Limbah Cair dari Industri Biskuit Dengan Proses Aerasi Bertingkat. Seminar Nasional Teknik Kimia Indonesia Yogyakarta," ISBN 979 97893-0-32003.

[9] M. Tahir, U. B. Khalid, and M. Waseem, "'Evaluation of Variation in Benefit Cost Ratio (bcr) and Yield of Mungbean (Vigna Radiata L.) due to Influence of Different Sources and Levels of Phosphorus," Custose agronegocio on line, vol. 11, pp. 23-34, 2015.

[10] A. Shaw, G. Wint, G. Cecchi, S. Torr, R. Mattioli, and T. Robinson, "Mapping the benefit-cost ratios of interventions against bovine trypanosomosis in Eastern Africa," Preventive veterinary medicine, vol. 122, pp. 406-416, 2015. 